\title{
Differential Effects of CBZ-Induced Catalysis and Cytochrome Gene Expression in Three Dimensional Zebrafish Liver Cell Culture Yoonah Jeong ${ }^{1}$, Chang-Beom Park', In-Hyuk Baek ${ }^{1}$, Kwanghun Jeong ${ }^{1,3}$, Seungyun Baik ${ }^{1,2^{*}}$ and Young Jun Kim ${ }^{1,3^{*}}$
}

${ }^{1}$ Environmental Safety Group, Korea Institute of Science and Technology Europe (KIST Europe), Forschungsgesellschaft mbH, Campus E7 1, Saarbruecken, Germany ${ }^{2}$ Department of Energy and Environmental Engineering, University of Science and Technology, Daejeon, Korea

${ }^{3}$ Department of Biomedical Engineering, University of Science and Technology, Daejeon, Korea

\begin{abstract}
Two dimensional (2D) cell cultures have been the standard in vitro model for environmental safety research. However, it does not properly mimic in vivo system which hampered cellular proliferation and differentiation over an extended culture time and quickly lost its function. In this study, we constructed a new three dimensional (3D) zebrafish liver cell model that more closely mimics the in vivo micro-environment for pharmaceuticals metabolism studies. The magnetic levitation method was used to maintain the controlled and uniform 3D spheroids. These spheroids were then tested with carbamazepine (CBZ) treatment to determine the applicability of this assay in metabolism study. The results demonstrated that the $3 \mathrm{D}$ cell model is more resistant to CBZ over $2 \mathrm{D}$ cell culture and in vivo and 3D culture cells are noticeable in CYP1a1 activity and the concentration of carbamazepine-10,11-epoxide (CBZ-EP) than 2D cell culture. This 3D cell culture model will provide useful information toward the development of improved biomimetic organ functions for alternatives to animal testing in environmental contaminants.
\end{abstract}

Keywords: Zebrafish liver cell (ZFL); Three dimensional (3D) cells; Carbamazepine (CBZ) carbamazepine-10,11-epoxide (CBZ-EP); Cytochrome P450 1a1 (CYP1a1); Alternatives to animal testing

\section{Introduction}

Concerns about the adverse effects of environmental contaminants have triggered research on zebrafish (Danio rerio), a vertebrate and one of the OECD toxicity testing organism, as a toxicity test model. The zebrafish is a promising species for evaluating chemical toxicity due to their rapid development, conserved molecular pathways and potential of high throughput screening [1-5]. The use of zebrafish also supports the 3Rs (reduction, refinement, and replacement) of animal use [6]. For these reasons, zebrafish liver (ZFL) cell lines can be used as a major target organ and adequately provided the unlimited supply of hepatocytes for metabolism testing at ease. In two dimensional (2D) cell cultures, ZFL has been shown the stable cytochrome P450 activities which can make the practical determination of chemical metabolism and toxicity. Among the CYP P450 subfamilies, CYP1a1 is the most well-known and sensitive to hepatocyte, which is a phase I drug metabolizing enzyme and a useful biomarker for analyzing the hepatocellular toxicity [7-9]. Therefore, the current use of the ZFL cell line as an in vitro model has proven to be efficient. However, 2D cell cultures tend to be extended in cell morphology, deplete hepatic polarity and lapse liver specific functions $[7,10,11]$. In addition, chronic chemical exposure could not be feasible in $2 \mathrm{D}$ cell culture due to the limitation of cellular surface and cell growths in long term. Cell growth in 3D spheroids generates endogenous extracellular matrix (ECM) surrounding the spheroids, while $2 \mathrm{D}$ monolayer has a homogenous cell layers probably with a contact with the culture plate. It has been shown that liver cell cultures in $3 \mathrm{D}$ models such as a hang in drop and a spinner bioreactor are significantly ameliorated the stability of CYP 450 expressions [12].

Carbamazepine (5H-dibenzo[b,f]azepine-5-carboxamide, CBZ) is an anti-epileptic drug and used for the treatment of epilepsy. With respect to the environmental issues, $\mathrm{CBZ}$ is of concern as one of the most frequently detected pharmaceutical residues in water bodies because this cannot be completely removed by the currently available water treatment systems [13-16]. Previous studies showed that environmentally relevant concentration of CBZ is not fatal to aquatic organisms, whereas chronic effects of CBZ include sub lethal impacts to aquatic organisms, decreased fecundity of Ceriodaphnia dubia, and reduced population growth rates of Daphnia pulex [17-21]. However, studies on ecotoxicological data through toxicological assessment of CBZ are limited [22]. In general, in vitro method is recognized as one of the useful tools for the hazard and risk assessment of various chemicals in a fairly short time of exposure [23]. In this study, therefore, we developed 3D spheroids of ZFL cells with in vitro 3D hepatocyte model as a simple and robust format of toxicity testing for CBZ.

The major primary metabolite of CBZ, carbamazepine-10,11epoxide (CBZ-EP), is an pharmacologically active metabolite of CBZ and an oxidized product formed by CYP450 enzymatic activity [2427]. Regarding the metabolism of CBZ exposed to in vitro systems, we also aim for the monitoring of CBZ-EP as the primary metabolite. In addition, owing to the distinct differences on cell cultures between 2D and 3D of pharmaceutics responses, we constructed 3D ZFL cell cultures using Nano shuttle methods. The different cell viabilities, CYP 450 inducibility and CBZ-EP metabolism were evaluated in this study. The acute hepatotoxicity responses to CBZ in zebrafish embryos were also studied for the potential allowances or limitations of these cell systems in environmental safety studies.

*Corresponding authors: Seungyun Baik, Environmental Safety Group, Korea Institute of Science and Technology Europe (KIST Europe), Forschungsgesellschaft mbH, Campus E7 1, Saarbruecken, Germany, Tel: +4906819382327; E-mail: sbaik@kist-europe.de

Young Jun Kim, Environmental Safety Group, Korea Institute of Science and Technology Europe (KIST Europe), Forschungsgesellschaft mbH, Campus E7 1, Saarbruecken Germany, Tel: +4906819382327; E-mail: youngjunkim@kist-europe.de

Received September 02, 2016; Accepted September 20, 2016; Published September 27, 2016

Citation: Jeong Y, Park CB, Baek IH, Jeong K, Baik S, et al. (2016) Differentia Effects of CBZ-Induced Catalysis and Cytochrome Gene Expression in Three Dimensional Zebrafish Liver Cell Culture. J Environ Anal Toxicol 6: 404. doi: 10.4172/2161-0525.1000404

Copyright: @ 2016 Jeong Y, et al. This is an open-access article distributed under the terms of the Creative Commons Attribution License, which permits unrestricted use, distribution, and reproduction in any medium, provided the original author and source are credited. 
Citation: Jeong Y, Park CB, Baek IH, Jeong K, Baik S, et al. (2016) Differential Effects of CBZ-Induced Catalysis and Cytochrome Gene Expression in Three Dimensional Zebrafish Liver Cell Culture. J Environ Anal Toxicol 6: 404. doi: 10.4172/2161-0525.1000404

Page 2 of 7

\section{Materials and Methods}

\section{Chemicals and reagents}

Carbamazepine (CBZ) was purchased from LGC standards (Augsburg, Germany) and 10,11-dihydro-10, 11-epoxycarbamazepine (CBZ-EP), 10,11-dihydro-trans-10,11-dihydroxy-carbamazepine (DiOH-CBZ) and carbamazepine-d10 (CBZ-d10), were supplied from Sigma Aldrich (Steinheim, Germany). Acetonitrile and methanol, LCMS grade, were purchased from VWR (Leuven, Belgium). Formic acid, ammonium acetate and dimethyl sulfoxide (DMSO) were provided from Sigma Aldrich. Stock solutions of CBZ were prepared in DMSO (10 mg/ $\mathrm{ml})$ and methanol $(0.5 \mathrm{mg} / \mathrm{ml})$ for the preparation of spiking solution to cell cultures and the analysis by liquid chromatography coupled with mass spectrometry (LC-MS), respectively. CBZ-EP and DiOH-CBZ stock solutions were prepared in methanol at a concentration of $10 \mathrm{mg} /$ $\mathrm{ml}$. All stock solutions were stored at $-20^{\circ} \mathrm{C}$ before the preparation of working solutions which were diluted by a relevant solvent. Working solutions containing $60 \mathrm{mg} / \mathrm{L}$ of $\mathrm{CBZ}$ were made by appropriate dilution in medium just before spiking in 96-well plate resulting in a final concentration of $30 \mathrm{mg} / \mathrm{L}$ in each well with the total volume of the cell culture mediums of $200 \mu \mathrm{l}$ for each well.

\section{Zebrafish embryo and ZFL cell cultures}

Embryos at 8 hours post fertilization from a wild-type adult zebrafish (AB 1880-0-3) were maintained under a long photoperiod (16L: $8 \mathrm{D}$ light/dark cycle) at $26 \pm 1^{\circ} \mathrm{C}$ water temperature in a climate room. The filtered tap water with Millipore $0.22 \mu \mathrm{m}$ GSWP filter (Merck, Darmstadt, Germany) after sterilization at $120^{\circ} \mathrm{C}$ for 2 hours were used as a supplemented media. Embryo toxicity tests were conducted in 6 well cell culture plate (Greiner Bio-one, Frickenhausen, Germany) filled with $10 \mathrm{~mL}$ per each test solution, and were performed with $30 \mu \mathrm{g} /$ $\mathrm{ml}$ of CBZ exposure test (3 replicates and 10 embryos per replicate). The mortality and the abnormality were recorded to assess the embryo toxicity based on phenotypic analysis. ZFL cells were purchased from ATCC $^{*}$ (Wesel, Germany), which were maintained in Dulbecco's Modified Eagle Medium (DMEM) plus 10\% fetal bovine serum (FBS) and $1 \%$ penicillin-streptomycin (P/S). After incubation, the cells were washed with PBS, trypsinized, and used for the spheroid formation. The ZFL cell line was maintained at $28^{\circ} \mathrm{C}$ in modified limit dilution factor (LDF) medium. ZFL were cultured in T-75 flasks. The phenol red-free LDF medium consists of 50\% Leibowitz-15 and 50\% DMEM/ F12, supplemented with $7.5 \mathrm{mM}$ Hepes (Sigma Aldrich, Steinheim, Germany) and $7.14 \mathrm{mM} \mathrm{NaHCO}_{3}$ (Sigma Aldrich, Steinheim, Germany) and 1\% penicillin-streptomycin-amphotericin (10,000 U/ $\mathrm{mL}$ potassium penicillin, $10,000 \mu \mathrm{g} / \mathrm{mL}$ streptomycin and $25 \mu \mathrm{g} / \mathrm{mL}$ amphotericin B; Sigma Aldrich, Steinheim, Germany). When used for cultivation, $5 \%$ FBS, $10 \mu \mathrm{g} / \mathrm{mL}$ human recombinant insulin, and $5 \mu \mathrm{g} / \mathrm{L}$ mouse epidermal growth factor (Sigma Aldrich, Steinheim, Germany) were added. One day prior to exposure, the cells were treated with $0.25 \%$ trypsin-ethylenediaminetetraacetic acid (EDTA, Sigma Aldrich, Steinheim, Germany), suspended in complete medium, and spun at 300 $\times \mathrm{g}$ in $5 \mathrm{~min}$. The pelleted cells were resuspended in $67 \%$ supplemented LDF medium and counted using Trypan Blue (Sigma Aldrich, Steinheim, Germany) exclusion method, before seeded in 6-well cell plates (Thermo Scientific, Waltham, MA, USA) with $5 \times 10^{5}$ cells per well in $2 \mathrm{~mL}$ supplemented $67 \%$ LDF medium. In contrast to the cultivation medium, the $67 \%$ LDF exposure medium contained $6.7 \mu \mathrm{g} / \mathrm{mL}$ insulin and $10 \%$ charcoal-stripped and heat-inactivated FBS.

\section{D cell culture by magnetic levitation methods}

The magnetic levitation (Nano3D bioscience, Huston, USA) was used to agglomerate cells into $3 \mathrm{D}$ cell cultures described by previous report [28]. For spheroid formation, a density of $1 \times 10^{5} \mathrm{ZFL}$ cells per $200 \mu \mathrm{L}$ was obtained. When the growth of cell is more than $80 \%$, the cell culture was treated in magnetic nanoparticles (n3D Biosciences, Houston, USA), for overnight. After detached, the cell were transferred in 24- or 96-well microplate at a density of $2 \times 10^{6}$ or $6 \times 10^{4}$ cells each well, which were magnetically levitated and cultured for four days. The culture medium was changed every two day. To examine the spheroid growth over time, 3D culture were captured from one to six days. The diameter of spheroid was measured and analyzed by image J software (SPSS, Inc, Chicago, IL, USA).

\section{MTT assay and live/cell staining}

MTT assay (Invitrogen Inc., Waltham, MA, USA) was performed to examine ZFL cell cytotoxicity and proliferation with and without CBZ treatment. The ZFL cells were first seeded on 96-well plates with a cell density of $1 \times 10^{4}$ per well and incubated overnight to achieve around $80 \%$ confluence. The medium was then removed and the cells were exposed to serum-free medium with $30 \mu \mathrm{g} / \mathrm{ml}$ of CBZ from $0 \mathrm{~h}$ to 72 hours. After exposure, the serum-free medium with the test chemicals was removed and $100 \mu \mathrm{L}$ medium with $5 \mathrm{mg} / \mathrm{mL}$ MTT was added to the wells and incubated for 4 hours. Supernatant was removed and $100 \mu \mathrm{L}$ of DMSO was supplemented to each well incubated for 10 min. Absorbance of samples was measured using a microplate reader (TECAN, Zurich, Switzerland) at $570 \mathrm{~nm}$. Cell viability of the ZFL spheroids was examined by a Live/Dead cell assay kit (Invitrogen Inc., Waltham, MA, USA). $1 \mu \mathrm{M}$ calcein-AM and $1 \mu \mathrm{M}$ ethidium homodimer were supplemented to the cell culture dish and incubated for $10 \mathrm{~min}$ at $37^{\circ} \mathrm{C}$. After washing with PBS, the cells were visualized with fluorescent microscopy (Olympusmicro, Shinjuku, Japan). To examine the initial cell distribution within the spheroids, cells were labeled with $1 \mu \mathrm{M}$ 5-chloromethyl fluorescein diacetate (CMFDA, green cell tracker dyes, Invitrogen Inc., Waltham, MA, USA) for $15 \mathrm{~min}$ prior to the spheroid formation.

\section{cDNA synthesis and real time polymerase chain reaction}

All samples from ZFL cells and embryos exposed to $30 \mu \mathrm{g} / \mathrm{ml}$ of CBZ as described above were collected for total RNA extraction using the Trizol reagent (Sigma Aldrich, Steinheim, Germany). For each samples, $0.3 \mathrm{ml}$ of supernatant of ZFL cell in culture media was mixed with $0.7 \mathrm{ml}$ of Trizol reagent and $0.2 \mathrm{ml}$ of chloroform. After centrifugation at $12,000 \mathrm{~g}$ for 10 minutes, the precipitated RNA in the aqueous solution was collected and washed with $70 \%$ ethanol and finally dissolved in $20 \mu \mathrm{l}$ of DEPC-treated water. To synthesis DNA templates for CYP and $\beta$-actin, the primers were designed and the cDNAs were amplified in real-time PCR by the primer pairs using SYBR green PCR kit (Invitrogen Inc., Waltham, MA, USA). The reaction was carried out with one cycle of reverse transcription at $45^{\circ} \mathrm{C}$ for one hour, followed by 40 cycle of amplification $\left(15 \mathrm{sec}\right.$ at $95^{\circ} \mathrm{C}, 30 \mathrm{sec}$ at $60^{\circ} \mathrm{C}$ and $30 \mathrm{sec}$ at $72^{\circ} \mathrm{C}$ ) and a final extension of $5 \mathrm{~min}$ at $72^{\circ} \mathrm{C}$ in a real time PCR system (Applied Biosystems, Foster City, CA, USA). The PCR sequences are followed as Table 1.

The relative gene expression of each samples were calculated as described using the formula of fluorescence intensities $\left(2^{\Delta \Delta \mathrm{Ct}}\right)$ in

\begin{tabular}{|c|c|}
\hline Name & Sequence $\left(\mathbf{5}^{\prime}\right.$-> $\left.\mathbf{3}^{\prime}\right)$ \\
\hline cyp 1a1_F & CGCTTGTATGGGCTTGTCCT \\
\hline cyp 1a1_R & CGCAGCTAAAACAGGCACTC \\
\hline$\beta$-actin_F & TGTCCCTGTATGCCTCTGGT \\
\hline$\beta$-actin_R & AAGTCCAGACGGAGGATGG \\
\hline
\end{tabular}

Table 1: Nucleotides sequences of primers in CYP $1 a 1$ and $\beta$-actin expression. 
Citation: Jeong Y, Park CB, Baek IH, Jeong K, Baik S, et al. (2016) Differential Effects of CBZ-Induced Catalysis and Cytochrome Gene Expression in Three Dimensional Zebrafish Liver Cell Culture. J Environ Anal Toxicol 6: 404. doi: 10.4172/2161-0525.1000404

Page 3 of 7

SPSS statistics computing software. Data are expressed as means \pm standard error of means (SEM) ( $\mathrm{n}=3$ per exposure concentration). Electrophoresis of each PCR product in $1.0 \%$ LE agarose gel was performed and following SYBR green staining, the results were viewed under the GelDoc image-analysis system (Bio-Rad, Hercules, CA, USA). Quantitative real-time PCR was performed on an iQ5 Multicolor Real-Time PCR Detection System (Bio-Rad Laboratories, Hercules, CA, USA). Results were further normalized using the calibrator cDNA of the positive control.

\section{Extraction of target chemicals}

A model chemical, CBZ, and its major metabolite, CBZ-EP, within the tested systems were extracted before analysis. The samples were collected at $0,24,48,72$ hour of exposure to analyze target chemicals. A $50 \mu \mathrm{l}$ aliquot of stored sample was mixed with $230 \mu \mathrm{l}$ of methanol. The mixture was then vigorously vortexed for 10 seconds and centrifuged at $13,000 \mathrm{~g}$ for 20 minutes. $250 \mu \mathrm{l}$ of methanol was then added to each sample and spun down again at $13,000 \mathrm{~g}$ for 20 minutes. After centrifugation, $100 \mu \mathrm{l}$ of the supernatant was transferred to HPLC vial and diluted 10 times with methanol. $20 \mu \mathrm{l}$ of CBZ-d10 was spiked in each vial as internal standard (nominal concentration of $50 \mathrm{ng} / \mathrm{ml}$ ) and stored at $-20^{\circ} \mathrm{C}$ until analysis.

\section{Liquid chromatography - mass spectrometry}

CBZ and CBZ-EP were analyzed by LC-MS/MS with Jetstream electrospray ionization (ESI). Liquid chromatography was performed by an Agilent 1290 series LC system (Agilent Technologies, CA, USA). Separation of the compounds was performed on a Zorbax Rapid Resolution High Definition column $(2.1 \mathrm{~mm} \times 50 \mathrm{~mm}, 1.8 \mu \mathrm{m}$ particle size, Agilent, Stuttgart, Germany) maintained at $30^{\circ} \mathrm{C}$. To protect the chromatographic column, a C18 guard column (Zorbax Eclipse Plus $2.1 \mathrm{~mm} \times 5 \mathrm{~mm}, 1.8 \mu \mathrm{m}$, Agilent, Stuttgart, Germany) was equipped with the column. A binary gradient consisting of two mobiles phases, Milli-Q water containing $5 \mathrm{mM}$ ammonium acetate and $0.1 \%$ formic acid (solvent $\mathrm{A}$ ) and LC/MS grade acetonitrile (solvent $\mathrm{B}$ ), was used. The initial conditions were $95 \% \mathrm{~A}$ and $5 \% \mathrm{~B}$, and $\mathrm{B}$ was increased to $20 \%$ in 4 minutes followed by increasing to $100 \%$ over 3.45 minutes. This condition was then held for 3.55 more minutes. The equilibration time was following for 1 more minute, which resulted in a total run time of 13 minutes including a post-run protocol. The flowrate was kept at $0.4 \mathrm{ml} / \mathrm{min}$ and the sample injection volume was set at $5 \mu \mathrm{l}$. Mass spectrometry was performed using an Agilent 6460 triplequadrupole mass spectrometer which was operated with ESI in positive mode. Mass spectrometric conditions include: gas temperature of $350^{\circ} \mathrm{C}$, gas flow of $10 \mathrm{~L} / \mathrm{min}$, nebulizer gas of $35 \mathrm{psi}$, capillary voltage of $4000 \mathrm{~V}$ and source temperature set to $400^{\circ} \mathrm{C}$. Nitrogen gas supplied by the nitrogen generator (F-DGSi, Evry, France) was used as a drying and a nebulizing gas. The MS analysis in multiple reaction monitoring
(MRM) mode was carried out using instrument setting described in Table 2. The accurate mass of precursor ions and the transitions to two product ions were monitored. The most abundant transition is used for quantification, whereas the second one is used to confirm the target analyte. Product ions with higher intensity were m/z 194.0 for CBZ and $\mathrm{m} / \mathrm{z} 179.8$ for CBZ-EP, which is in accordance with the previous study determined CBZ in human plasma using LC-MS/MS [29]. These source and fragmentation parameters were optimized for each analyte using $100 \mathrm{pg} / \mathrm{ml}$ of a single standard dissolved in methanol, by passing the same column explained in the method. Calibration curves were established at nine levels for each analyte ranged from 1.95 to $500 \mathrm{ng} /$ $\mathrm{ml}$ with a correlation coefficient $\mathrm{R}^{2}>0.99$. The concentrations of all measurements were recalculated according to the appropriate dilution factors. Instrumental limit of detection (ILOD) and instrumental limit of quantification (ILOQ) values were estimated from the low concentration calibration standard giving a signal-to-noise ratio of 3:1 and 10:1, respectively. ILOD values of $120 \mathrm{pg} / \mathrm{ml}$ for CBZ and 129 $\mathrm{pg} / \mathrm{ml}$ for CBZ-EP were achieved. Agilent MassHunter Qualitative Analysis and Quantitative Analysis software (v.B.06.00) were used for data processing.

\section{Extraction yield}

Preliminary experiment to evaluate the extraction recoveries was performed with supplemented medium at concentrations of 10 and 2 $\mu \mathrm{g} / \mathrm{ml}$ for CBZ and CBZ-EP, respectively $(\mathrm{n}=3)$. Previously described extraction procedure was applied to prepared samples and injected into the LC-MS/MS system for the analysis. Extraction recoveries of target compounds from this method are in Table 3.

\section{Statistical analysis}

All data are expressed as mean \pm standard error of mean (SEM). A two-way analysis of variance (ANOVA) was used to assess the differences in in vitro and in vivo system for CBZ-EP determination. Statistical significance was set at $\mathrm{p}<0.05$

\section{Results and Discussion}

\section{Morphology of 2D and 3D cell culture}

The morphologies of $2 \mathrm{D}$ cell and 3D cells were observed with bright field microscopy as shown in Figure 1. Cell morphology was investigated from day 2 to day 6 after cell seeding. Bright field microscopy showed that $2 \mathrm{D}$ cells were spread and forming monolayer with irregular cell morphology, whereas the cells in 3D were with spheroid formation. Uniform 3D spheroids with the diameter between 350 and $400 \mu \mathrm{m}$ were obtained after two days culture by magnetic levitation methods. The $3 \mathrm{D}$ cell culture became to form spheroid in suspension and initially decreased diameter and transparency due to compact cellular reorganization. The spheroid diameter then increased continuously after two days culture.

\begin{tabular}{|c|c|c|c|c|c|c|}
\hline Compounds & RT (min) & Transitions & $\mathrm{FV}(\mathrm{V})$ & CE (V) & $\begin{array}{l}\text { ILOD } \\
\text { (ng/L) }\end{array}$ & $\begin{array}{l}\text { ILOQ } \\
\text { (ng/L) }\end{array}$ \\
\hline \multirow{2}{*}{$\mathrm{CBZ}$} & \multirow{2}{*}{7.2} & $237.0 \rightarrow 194.0$ (quantifier) & 80 & 20 & \multirow{2}{*}{120} & \multirow{2}{*}{399} \\
\hline & & $237.0 \rightarrow 165.0$ (qualifier) & 80 & 50 & & \\
\hline \multirow{2}{*}{ CBZ-EP } & \multirow{2}{*}{6.6} & $253.1 \rightarrow 179.8$ (quantifier) & 85 & 36 & \multirow{2}{*}{129} & \multirow{2}{*}{429} \\
\hline & & $253.1 \rightarrow 235.8$ (qualifier) & 85 & 8 & & \\
\hline \multirow{2}{*}{$\begin{array}{c}\text { CBZ-d10 } \\
\text { (Internal standard) }\end{array}$} & \multirow{2}{*}{7.1} & $247.2 \rightarrow 203.9$ (quantifier) & 110 & 40 & \multirow{2}{*}{ N.A. } & \multirow{2}{*}{ N.A. } \\
\hline & & $247.2 \rightarrow 201.9$ (qualifier) & 110 & 20 & & \\
\hline
\end{tabular}

\section{N.A.: Not Applicable}

Table 2: LC-MS/MS conditions applied in a positive mode for the quantification of compounds. Retention Time (RT), MRM transitions selected, Fragment Voltage (FV), Collision Energy (CE), Instrumental Limits of Detection (ILOD) and Quantification (ILOQ) are indicated in this table. 
Citation: Jeong Y, Park CB, Baek IH, Jeong K, Baik S, et al. (2016) Differential Effects of CBZ-Induced Catalysis and Cytochrome Gene Expression in Three Dimensional Zebrafish Liver Cell Culture. J Environ Anal Toxicol 6: 404. doi: 10.4172/2161-0525.1000404

Page 4 of 7

\begin{tabular}{|c|c|c|c|}
\hline \multirow{2}{*}{ CBZ-EP recovery (\%) } & Sample & 2D cells & \multicolumn{2}{|c|}{ ZD cells } \\
\cline { 2 - 4 } & In vitro & & $97.10( \pm 3.93)$ \\
\hline \multirow{3}{*}{ CBZ-EP concentration $(\mathbf{n g} / \mathbf{m l})$} & In vivo & N.A & N.A \\
\cline { 2 - 4 } & Day 0 & N.A & N.A \\
\cline { 2 - 4 } & Day 1 & $0.12( \pm 0.01)$ & $0.10( \pm 0.07)$ \\
\cline { 2 - 4 } & Day 2 & $0.16( \pm 0.02)$ & $0.01)$ \\
\hline
\end{tabular}

Table 3: CBZ-EP concentration $(\mathrm{ng} / \mathrm{ml})$ in time course following a single dose of $30 \mu \mathrm{g} / \mathrm{ml} \mathrm{CBZ}$. All data enlisted are the average of triplicate and standard deviation from mean.

2D Cell culture

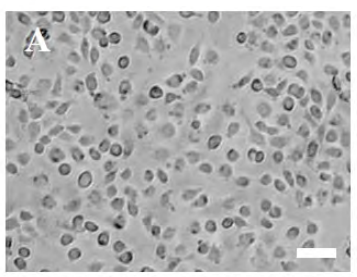

3D Cell culture

Day 2
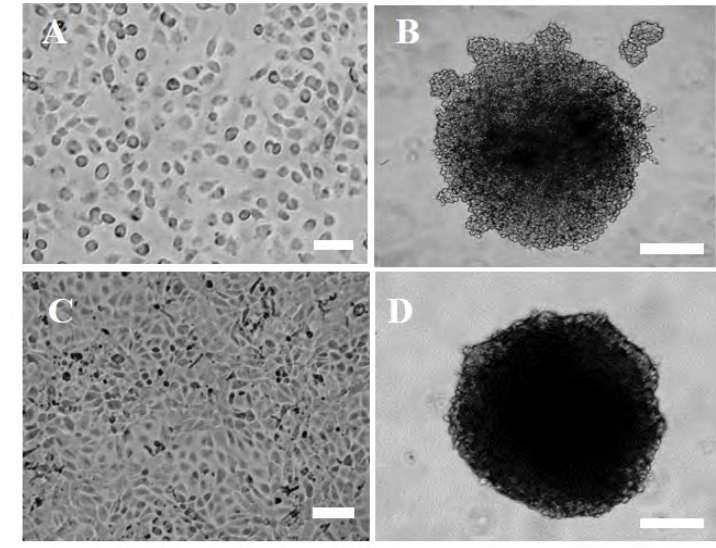

Day 4
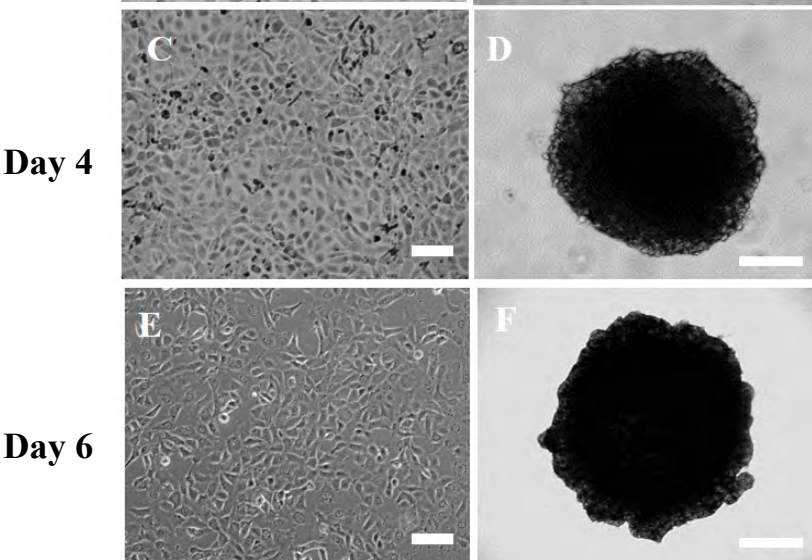

Figure 1: Bright field images of ZFL morphology in 2D monolayer and 3D spheroid on day 2, 4 and 6, respectively (Scale bar indicates $100 \mu \mathrm{m}$ ).

\section{Expression of liver specific Cytochrome P450 gene}

CYP 450 induction is one of the most important catalytic metabolism for pharmaceutical function and xenobiotics [30]. The mRNA levels of CYP1al were measured by RT-PCR at different concentration for 3 days. As shown in Figure 2A), CYP 450 levels of $2 \mathrm{D}$ cells, $3 \mathrm{D}$ cells and Zebrafish embryo were comparable and higher in the 3D cell and Zebrafish embryo than those in 2D monolayer from the point of $7 \mu \mathrm{g} / \mathrm{ml} \mathrm{CBZ}$. Fold changes of CYP1a1 mRNA reached saturation peak around $30 \mu \mathrm{g} / \mathrm{ml} \mathrm{CBZ}$, exhibited by 1.5 fold for $2 \mathrm{D}$ cell, 2.5 fold for 3D cell and 3.25 fold for Zebrafish embryo at day 3 of exposure compared to basal level of CYP1a1 at day 0 , respectively. Hence, $30 \mu \mathrm{g} / \mathrm{ml}$ treatment was fixed to treat all experimental groups in this work. This concentration is also meaningful because it was found as no observed effect concentration (NOEC) for Zebrafish embryo by van den Brandhof et al. [31]. Subsequently we investigate of CYP1a1 mRNA levels on day 3 following a single dose of $30 \mu \mathrm{g} / \mathrm{ml} \mathrm{CBZ} \mathrm{in}$ 2D cell, 3D cell and Zebra embryo (Figure 2B). After $30 \mu \mathrm{g} / \mathrm{ml} \mathrm{CBZ}$ exposure, we observed CYP1a1 levels of 3D and Zebrafish embryo dramatically increased those in $2 \mathrm{D}$ cell from the 12 hours, which is significant biomarker for in vivo liver. Quite interestingly, the 3D cell cultures exhibited a relatively higher mRNA expression at initial time whereas, undeveloped zebrafish embryo exhibited low levels of mRNA at 0 time that $3 \mathrm{D}$ cell could be regarded as a key biomarker of mature hepatocytes of adult Zebrafish.

\section{D, 3D Cell and Embryo changes in morphology and viability}

Cell viability was determined in both $2 \mathrm{D}$ and $3 \mathrm{D}$ cell cultures albeit morphological changes of embryo in the presence of $30 \mu \mathrm{g} / \mathrm{ml} \mathrm{CBZ}$. As shown in Figure 3A, live/dead cell staining was performed with 1 $\mu \mathrm{M}$ calcein-AM and ethidium homodimer to examine the cell viability. Highly compact 3D cell spheroid were formed with live cells even in the presence of $30 \mu \mathrm{g} / \mathrm{ml} \mathrm{CBZ}$. Most of cells and only few cells turned to red for dead cells, whereas higher $2 \mathrm{D}$ cell death were observed both in the presence and absence of $30 \mu \mathrm{g} / \mathrm{ml} \mathrm{CBZ} \mathrm{exposure} \mathrm{at} \mathrm{day} 3$. There is no morphological change in both control and $30 \mu \mathrm{g} / \mathrm{ml} \mathrm{CBZ}$ exposure group (Figure $3 \mathrm{~B}$ ), indicating that the exposure to $30 \mu \mathrm{g} / \mathrm{ml}$ CBZ has non-toxic effect on zebrafish embryo. MTT assay exhibited higher cell viability in $3 \mathrm{D}$ cell culture than those in $2 \mathrm{D}$ cell culture 30 $\mu \mathrm{g} / \mathrm{ml} \mathrm{CBZ}$ exposures as shown in Figure 3C. Over the three days of 2D cell cultures, treatment with $30 \mu \mathrm{g} / \mathrm{ml} \mathrm{CBZ}$ resulted in $90 \%, 84 \%$ and $79 \%$ cell viability on day 1, 2 and 3 , respectively. By contrast the $3 \mathrm{D}$ cell culture with $30 \mu \mathrm{g} / \mathrm{ml} \mathrm{CBZ}$ exhibited no significant change in cell viability and resulted in $105 \%, 98 \%$ and $95 \%$ on day 1,2 and 3 , respectively. It demonstrated that $3 \mathrm{D}$ cell culture has higher $\mathrm{CBZ}$ resistance than $2 \mathrm{D}$ culture. In line with those results, spheroid diameter increased by $20 \%$ for CBZ treated 3D cell culture and 35\% for control in day 3 , indicating that there were no statistically significant differences over the 3 days of exposure with cell culture shown in Figure 3D. It can be concluded that $3 \mathrm{D}$ cell culture and healthy zebrafish embryo has similar CBZ resistance at $30 \mu \mathrm{g} / \mathrm{ml}$. Higher CBZ resistance can be explained by CBZ diffusion through the extracellular matrix may be hampered in the $3 \mathrm{D}$ cell spheroid, which leads to decreased drug delivery to inner layer and lower toxicity than $2 \mathrm{D}$ cell and tight cell to cell interaction may improve cell viability and proliferation.

\section{Transformation of CBZ to CBZ-EP}

It is well known that the hepatocytes convert CBZ to CBZ-EP, one of the primary metabolites, and further to DiOH-CBZ $[9,30,32,33]$. $\mathrm{DiOH}-\mathrm{CBZ}$ in all samples were not detected. Therefore, to validate catalytic activities of $\mathrm{CBZ}$ on $2 \mathrm{D}$ and $3 \mathrm{D}$ cell cultures as well as zebrafish embryos, quantification of CBZ-EP in samples at different exposed times of $0,1,2$, and 3 days was performed by using LC-MS/MS and the results were shown in Figure 4 and Table 3. The chemical extraction procedure was successfully applied to all sample preparations. Applied procedure for all samples appeared to produce the fairly consistent and reproducible recoveries as shown in Table 3 . The concentrations of CBZ-EP for tested 2D and 3D cell cultures at 0 Day were not applicable due to their lower values than the detection limit (Figure 4 and Table 3). Interestingly, Zebrafish embryo at 0 day resulted in $5.04 \mu \mathrm{g} / \mathrm{L}$ of CBZ-EP. It can be assumed that CYP P450 in lethal embryo at 0 day was functionalized and maintain their CBZ binding activities and rapid turnover epoxidation of CBZ during sample preparation at room temperature. For all samples, the amount of CBZ-EP was increased continuously from day 1 as the results of quantitative analysis (Figure 4B). Time dependent and rapid CBZ metabolism presented in this 
Citation: Jeong Y, Park CB, Baek IH, Jeong K, Baik S, et al. (2016) Differential Effects of CBZ-Induced Catalysis and Cytochrome Gene Expression in Three Dimensional Zebrafish Liver Cell Culture. J Environ Anal Toxicol 6: 404. doi: 10.4172/2161-0525.1000404
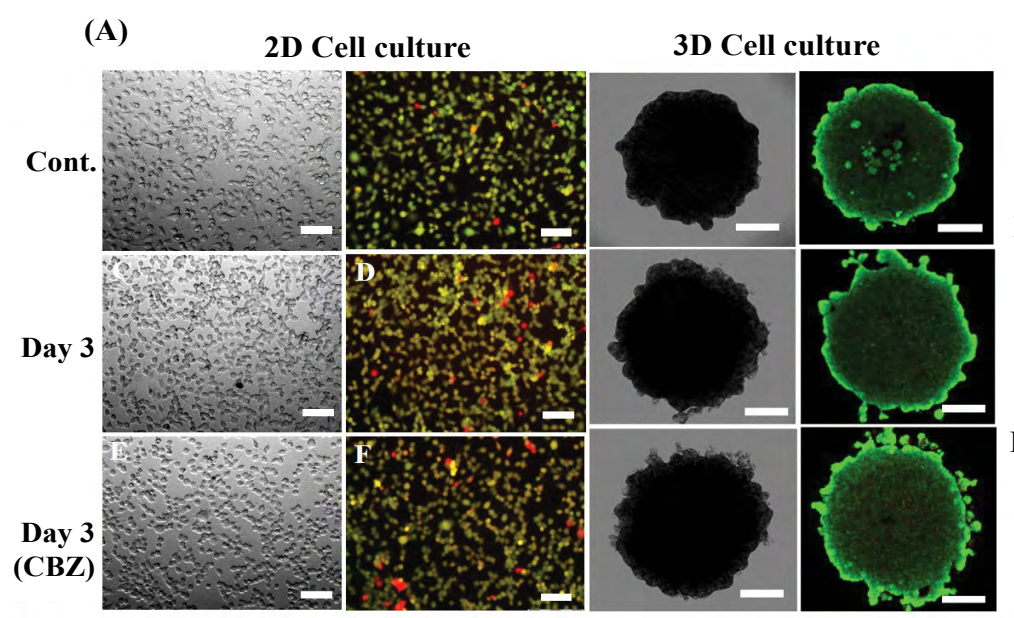

(B)
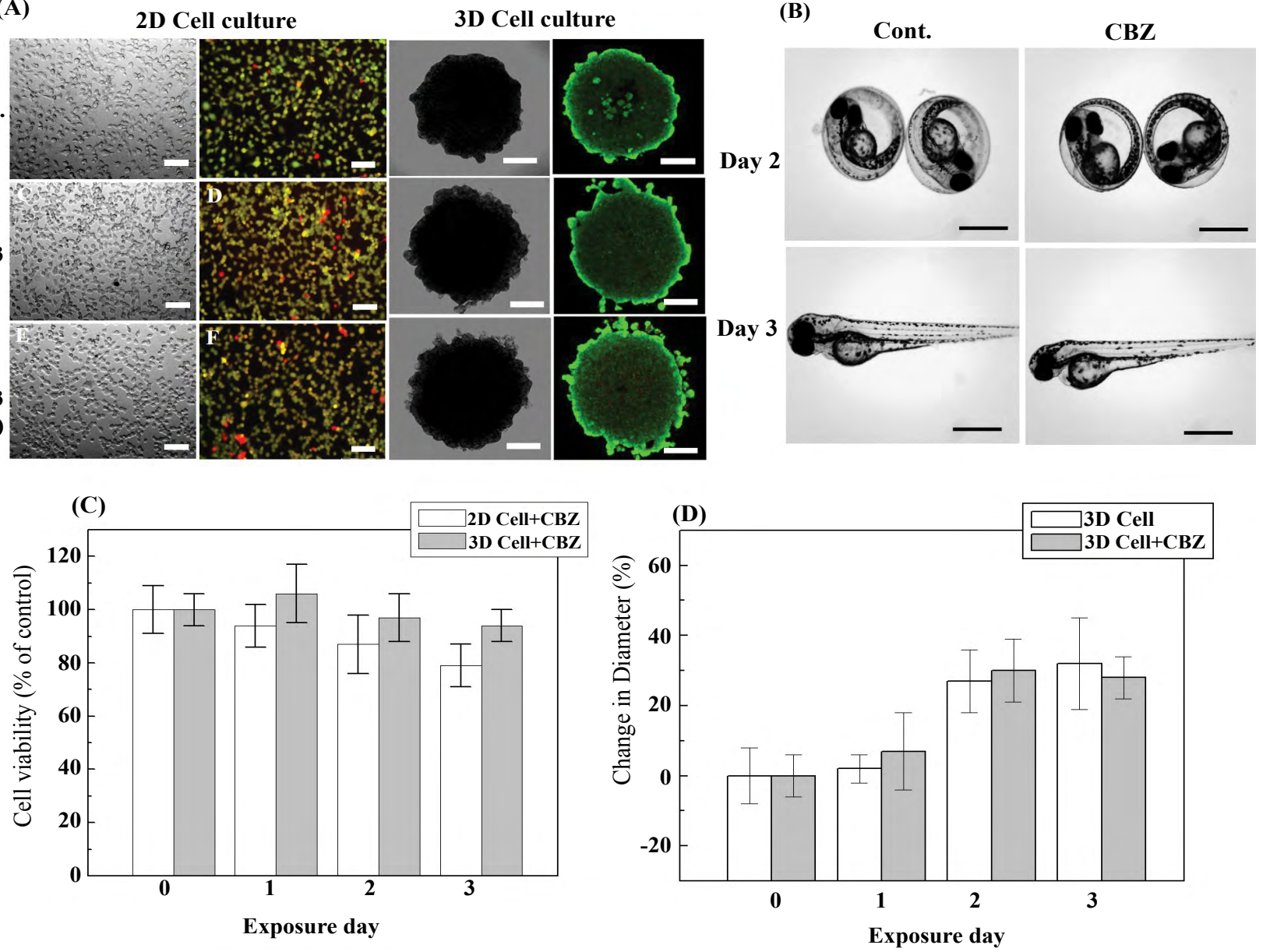

Figure 2: Morphological changes and cell viability of $2 \mathrm{D}$ and $3 \mathrm{D}$ cells formed by magnetic levitation and Zebrafish embryo in the presence of $30 \mu \mathrm{g} / \mathrm{ml} \mathrm{CBZ}$ (day 0,1 2 and 3); (A) Live/Dead cell assay of ZFL on day 3 (Scale bar indicates $100 \mu \mathrm{m}$ ); (B) Microscopic images of zebrafish embryos at day 2 and 3 after fertilization (Scale bar $=500 \mu \mathrm{m}$.); Cell viability, C) $30 \mu \mathrm{g} / \mathrm{ml}$ CBZ in 2D and 3D cells, D) Comparison of 3D spheroid growth (\%) in time course in the presence of 30 $\mu \mathrm{g} / \mathrm{ml}$ CBZ . Data are presented at the mean \pm SEM of three sets of independent experiments.

(A)

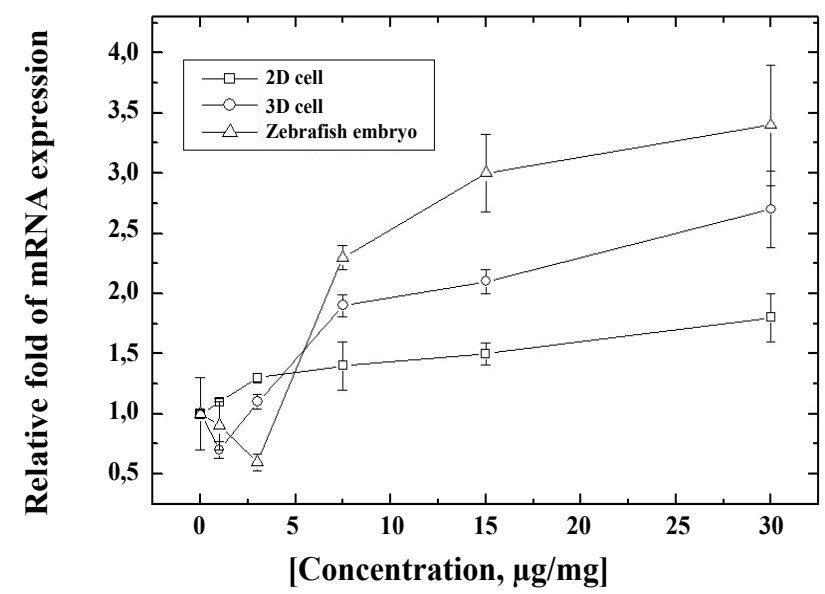

(B)

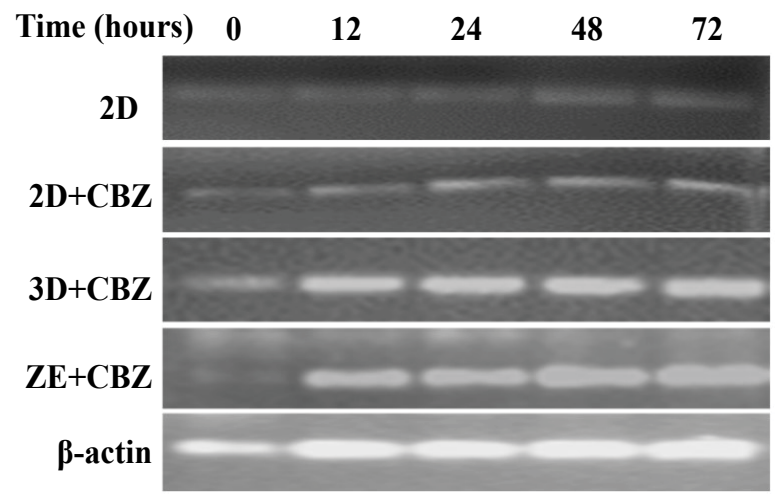

Figure 3:CYP 1a1 induction using CBZ in the 2D, 3D cells and Zebrafish embryo. mRNA expression levels of CYP1a1 at different concentrations (A) Corresponded agarose gel loading of $30 \mu \mathrm{g} / \mathrm{ml}$ CBZ treated samples in time course (B) The results repeated in triplicate with the data presented in the mean \pm SEM. 
Citation: Jeong Y, Park CB, Baek IH, Jeong K, Baik S, et al. (2016) Differential Effects of CBZ-Induced Catalysis and Cytochrome Gene Expression in Three Dimensional Zebrafish Liver Cell Culture. J Environ Anal Toxicol 6: 404. doi: 10.4172/2161-0525.1000404

(A)

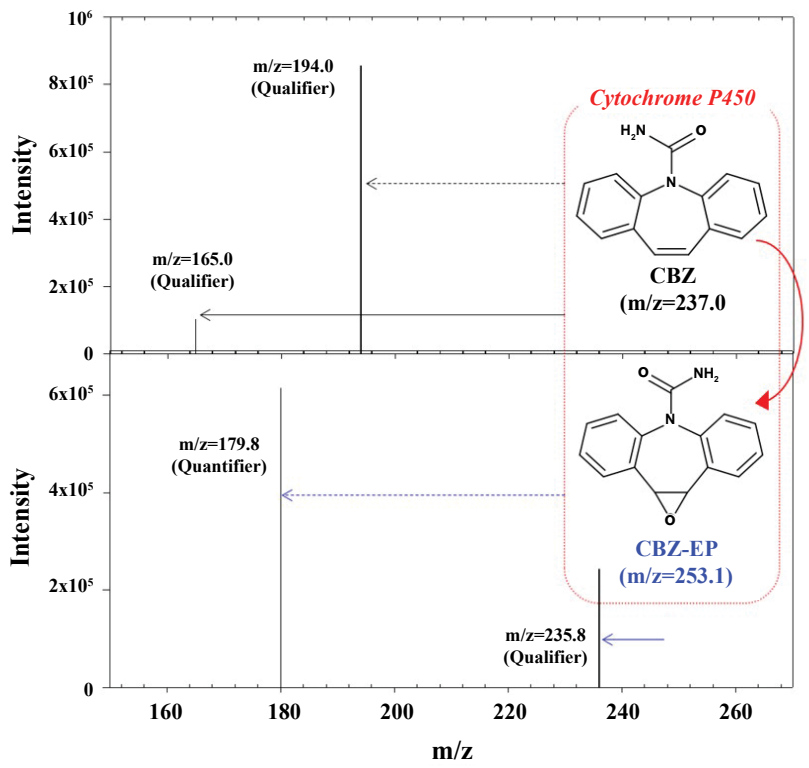

(B)

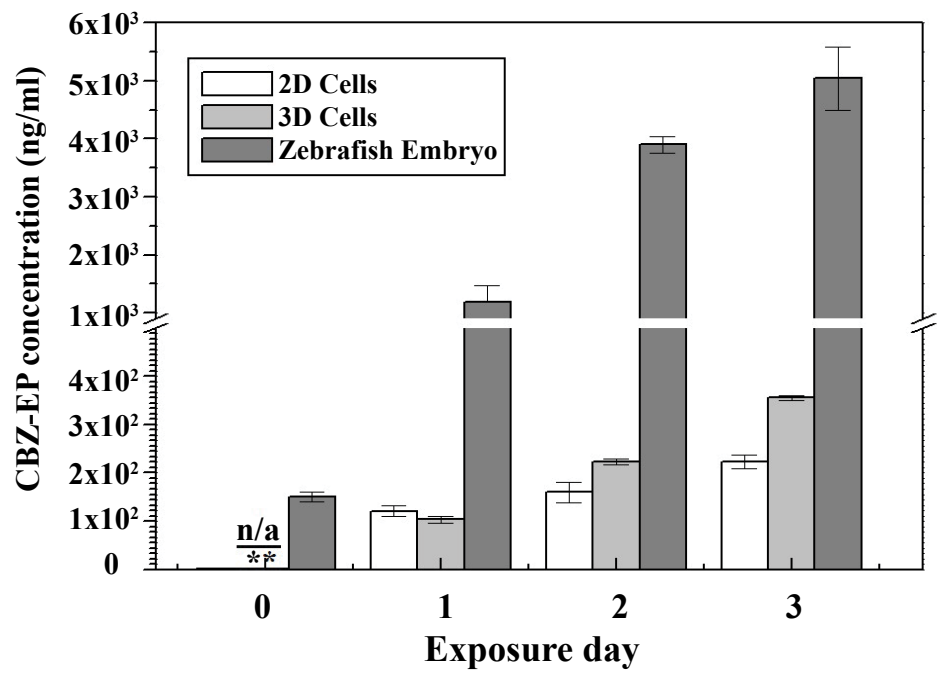

Figure 4: (A) MS/MS transitions including quantifier and qualifier for CBZ and CBZ-EP, (B) CBZ-EP concentrations at different exposure time, 24, 48, and 72 hours $(n=3)$, from $2 D, 3 D Z F L$ cell cultures and Zebrafish embryo are tested. Each cell culture sample was exposed to $30 \mu \mathrm{g} / \mathrm{ml}$ of $C B Z$ and extracted for the quantification of CBZ-EP.

study has been reported previously [8]. CBZ treatment clearly induced higher epoxidation activities in zebrafish embryo $(5.04 \mu \mathrm{g} / \mathrm{L}$ per 10 embryos) than $2 \mathrm{D}\left(0.22 \mu \mathrm{g} / \mathrm{L}\right.$ per $1 \times 10^{6}$ seeding cells $)$ and $3 \mathrm{D}(0.30$ $\mu \mathrm{g} / \mathrm{L}$ per $1 \times 10^{6}$ seeding cells) cell culture at last sampling point (the values of day 3 in Table 3 ). It is obvious that $3 \mathrm{D}$ cell culture had higher metabolic activities for CBZ as showing higher conversion values of CBZ-EP compared to 2D cell culture. Gagne et al. described that CBZ may induce rather CYP2 or CYP3 genes, not CYP1s under in vitro condition of piscine species [34]. However, the expression of CYP3a65 in this study did not show clear gene expression in time dependency in the presence of $30 \mu \mathrm{g} / \mathrm{ml} \mathrm{CBZ} \mathrm{(SI).} \mathrm{It} \mathrm{can} \mathrm{be} \mathrm{assumed} \mathrm{that} \mathrm{mRNA}$ level of CYP 450 (CYP3a65) is the hepatotoxicity biomarker but might not be deeply involved in epoxidation of CBZ. Accordingly, the epoxidation of CBZ can be mainly induced by the other subfamily of CYP 450 enzyme. The higher CBZ-EP levels in embryo provide the evidence to support notion that liver specific CBZ-EP metabolism were improved in the $3 \mathrm{D}$ cell cultures compared with $2 \mathrm{D}$ cell cultures.

\section{Conclusions}

In this study, ZFL 2D, 3D cell culture and Zebrafish embryo were compared to evaluate the potential of $3 \mathrm{D}$ cell culture as an in vitro hepatic toxicity and metabolism study. Culturing ZFL cells into $3 \mathrm{D}$ spheroids can be promoted to overcome the limitation of $2 \mathrm{D}$ in vitro culture and provide similar CBZ metabolism with zebrafish embryo assay because $3 \mathrm{D}$ cell culture recapitulates the dimensionality of the liver tissue, hence it provided functions more similar to an in vivo model. The higher cell viabilities, particularly with respect to high inducibility of CYP 450 metabolism, is important for organotypic function for the continued cell proliferation and dimensionality when compared to Zebrafish embryo. The 3D cell culture developed in this study can be applicable to the environmental toxicity testing. Our results also provided the feasibility of 3D cell culture in high throughput screening toward the development of alternative to animal model for chemical safety screening.

\section{Acknowledgments}

This research was supported by the basic fund project 11605 of Korea Institute of Science and Technology Europe (KIST Europe). YN Jung, CB Park and IH Baek contributed this work equally. YJ Kim and SY Baik as a correspondence designed the works and written manuscripts with proofreading.

\section{References}

1. Kari G, Rodeck U, Dicker AP (2007) Zebrafish: an emerging model system for human disease and drug discovery. Clinical Pharmacology \& Therapeutics 82: 70-80.

2. McGrath P, Li CQ (2008) Zebrafish: a predictive model for assessing druginduced toxicity. Drug discovery today 13: 394-401.

3. Lammer E, Carr GJ, Wendler K, Rawlings JM, Belanger SE, et al. (2009) Is the fish embryo toxicity test (FET) with the zebrafish (Danio rerio) a potential alternative for the fish acute toxicity test?. Comparative Biochemistry and Physiology Part C: Toxicology \& Pharmacology 149: 196-209.

4. Eimon PM, Rubinstein AL (2009) The use of in vivo zebrafish assays in drug toxicity screening. Expert Opin Drug Metab Toxicol 5: 393-401.

5. Scholz S, Büttner A, Klüver N, Guinea J (2010) 13 Fish embryos as alternative models for drug safety evaluation. Predictive Toxicology in Drug Safety 27:244.

6. Russell WMS, Burch RL, Hume CW (1959) The principles of humane experimental technique.

7. Darnell M, Schreiter T, Zeilinger K, Urbaniak T, Söderdahl T, et al. (2011) Cytochrome P450-dependent metabolism in HepaRG cells cultured in a dynamic three-dimensional bioreactor. Drug Metab Dispos 39: 1131-1138.

8. Pelkonen O, Myllynen P, Taavitsainen P, Boobis AR, Watts P, et al. (2001) Carbamazepine: a'blind'assessment of CYP-associated metabolism and interactions in human liver-derived in vitro systems. Xenobiotica 31: 321-343.

9. Mesdjian E, Sérée E, Charvet B, Mirrione A, Bourgarel-Rey V, et al. (1999) Metabolism of carbamazepine by CYP3A6: a model for in vitro drug interactions studies. Life Sci 64: 827-835.

10. Godoy P, Hewitt NJ, Albrecht U, Andersen ME, Ansari N, et al. (2013) Recent advances in $2 \mathrm{D}$ and $3 \mathrm{D}$ in vitro systems using primary hepatocytes, alternative hepatocyte sources and non-parenchymal liver cells and their use in investigating mechanisms of hepatotoxicity, cell signaling and ADME. Archives of toxicology 87 : $1315-530$. 
Citation: Jeong Y, Park CB, Baek IH, Jeong K, Baik S, et al. (2016) Differential Effects of CBZ-Induced Catalysis and Cytochrome Gene Expression in Three Dimensional Zebrafish Liver Cell Culture. J Environ Anal Toxicol 6: 404. doi: 10.4172/2161-0525.1000404

11. Leite SB, Wilk-Zasadna I, Zaldivar JM, Airola E, Reis-Fernandes MA, et al. (2012) Three-dimensional HepaRG model as an attractive tool for toxicity testing. Toxicol Sci 130: 106-116.

12. Gunness $P$, Mueller D, Shevchenko V, Heinzle E, Ingelman-Sundberg M, et al. (2013) 3D organotypic cultures of human HepaRG cells: a tool for in vitro toxicity studies. Toxicol Sci 133: 67-78.

13. Bahlmann A, Brack W, Schneider RJ, Krauss M (2014) Carbamazepine and its metabolites in wastewater: Analytical pitfalls and occurrence in Germany and Portugal. Water Res 57: 104-114.

14. Loos R, Gawlik BM, Locoro G, Rimaviciute E, Contini S, et al. (2009) EU-wide survey of polar organic persistent pollutants in European river waters. Environ Pollut 157: 561-568.

15. Loos R, Carvalho R, António DC, Comero S, Locoro G, et al. (2013) EU-wide monitoring survey on emerging polar organic contaminants in wastewater treatment plant effluents. Water research 47: 6475-6487.

16. Zhang Y, Geißen SU, Gal C (2008) Carbamazepine and diclofenac: removal in wastewater treatment plants and occurrence in water bodies. Chemosphere 73: $1151-1161$

17. Lamichhane K, Garcia SN, Huggett DB, DeAngelis DL, La Point TW (2013) Chronic effects of carbamazepine on life-history strategies of Ceriodaphnia dubia in three successive generations. Archives of environmental contamination and toxicology $64: 427-438$.

18. Lürling MF, Sargant E, Roessink I (2006) Life-history consequences for Daphnia pulex exposed to pharmaceutical carbamazepine. Environmental toxicology 21: 172-180.

19. Bennett GD, Amore BM, Finnell RH, Wlodarczyk B, Kalhorn TF, et al. (1996) Teratogenicity of carbamazepine-10, 11-epoxide and oxcarbazepine in the SWV mouse. J Pharmacol Exp Ther 279: 1237-1242.

20. Galus M, Kirischian N, Higgins S, Purdy J, Chow J, et al. (2013) Chronic, low concentration exposure to pharmaceuticals impacts multiple organ systems in zebrafish. Aquatic toxicology 132: 200-211.

21. Hartwig C, Muth-Köhne E, Düring RA (2013) Screening for ecotoxicological effects of antiepileptic drugs in biologically treated waste water originating from an epilepsy ward by Danio rerio embryos. Environmental Sciences Europe 25: 1.

22. Li ZH, Zlabek V, Velisek J, Grabic R, Machova J, et al. (2011) Acute toxicity of carbamazepine to juvenile rainbow trout (Oncorhynchus mykiss): effects on antioxidant responses, hematological parameters and hepatic EROD. Ecotoxicology and environmental safety $74:$ 319-327.

23. Wilk-Zasadna I, Bernasconi C, Pelkonen O, Coecke S (2015) Biotransformation in vitro: An essential consideration in the quantitative in vitro-to-in vivo extrapolation (QIVIVE) of toxicity data. Toxicology 332: 8-19.

24. Kerr BM, Thummel KE, Wurden CJ, Klein SM, Kroetz DL, et al. (1994) Human liver carbamazepine metabolism: role of CYP3A4 and CYP2C8 in 10 11-epoxide formation. Biochemical pharmacology 47: 1969-1979.

25. Yoshimura R, Yanagihara N, Terao T, Minami K, Toyohira Y, et al. (1998) An active metabolite of carbamazepine, carbamazepine-10, 11 -epoxide, inhibits ion channel-mediated catecholamine secretion in cultured bovine adrenal medullary cells. Psychopharmacology135: 368-373.

26. Yuki H, Honma T, Hata M, Hoshino T (2012) Prediction of sites of metabolism in a substrate molecule, instanced by carbamazepine oxidation by CYP3A4. Bioorg Med Chem 20: 775-783.

27. Vignati L, Turlizzi E, Monaci S, Grossi P, De Kanter R, et al. (2005) An in vitro approach to detect metabolite toxicity due to CYP3A4-dependent bioactivation of xenobiotics. Toxicology 216: 154-167.

28. Timm DM, Chen J, Sing D, Gage JA, Haisler WL, et al. (2013) A highthroughput three-dimensional cell migration assay for toxicity screening with mobile device-based macroscopic image analysis. Scientific reports 3:3000.

29. Breton $H$, Cociglio M, Bressolle F, Peyriere H, Blayac JP, et al. (2005) Liquid chromatography-electrospray mass spectrometry determination of carbamazepine, oxcarbazepine and eight of their metabolites in human plasma. Journal of Chromatography B 828: 80-90.

30. Shokry E, Villanelli F, Malvagia S, Rosati A, Forni G, et al. (2015) Therapeutic drug monitoring of carbamazepine and its metabolite in children from dried blood spots using liquid chromatography and tandem mass spectrometry. Journal of pharmaceutical and biomedical analysis 109: 164-170.

31. van den Brandhof EJ, Montforts M (2010) Fish embryo toxicity of carbamazepine diclofenac and metoprolol. Ecotoxicol Environ Saf 73: 1862-1866.

32. Van Rooyen GF, Badenhorst D, Swart KJ, Hundt HK, Scanes T, et al. (2002) Determination of carbamazepine and carbamazepine 10,11-epoxide in human plasma by tandem liquid chromatography-mass spectrometry with electrospray ionisation. J Chromatogr B Analyt Technol Biomed Life Sci 769: 1-7.

33. Zhu Y, Chiang H, Wulster-Radcliffe M, Hilt R, Wong P, et al. (2005) Liquid chromatography/tandem mass spectrometry for the determination of carbamazepine and its main metabolite in rat plasma utilizing an automated blood sampling system. Journal of pharmaceutical and biomedical analysis 38 : 119-125.

34. Gagné F, Blaise C, André C (2006) Occurrence of pharmaceutical products in a municipal effluent and toxicity to rainbow trout (Oncorhynchus mykiss) hepatocytes. Ecotoxicology and Environmental Safety 64: 329-336. 